\title{
Review Article \\ Targeting the Mitotic Catastrophe Signaling Pathway in Cancer
}

\author{
Margaret M. Mc Gee \\ School of Biomolecular and Biomedical Science, Conway Institute, University College Dublin, Belfield, Dublin 4, Ireland \\ Correspondence should be addressed to Margaret M. Mc Gee; margaret.mcgee@ucd.ie
}

Received 22 December 2014; Accepted 30 May 2015

Academic Editor: Anshu Agrawal

Copyright (C) 2015 Margaret M. Mc Gee. This is an open access article distributed under the Creative Commons Attribution License, which permits unrestricted use, distribution, and reproduction in any medium, provided the original work is properly cited.

\begin{abstract}
Mitotic catastrophe, as defined in 2012 by the International Nomenclature Committee on Cell Death, is a bona fide intrinsic oncosuppressive mechanism that senses mitotic failure and responds by driving a cell to an irreversible antiproliferative fate of death or senescence. Thus, failed mitotic catastrophe can promote the unrestrained growth of defective cells, thereby representing a major gateway to tumour development. Furthermore, the activation of mitotic catastrophe offers significant therapeutic advantage which has been exploited in the action of conventional and targeted anticancer agents. Yet, despite its importance in tumour prevention and treatment, the molecular mechanism of mitotic catastrophe is not well understood. A better understanding of the signals that determine cell fate following failed or defective mitosis will reveal new opportunities to selectively target and enhance the programme for therapeutic benefit and reveal biomarkers to predict patient response. This review is focused on the molecular mechanism of mitotic catastrophe induction and signalling and highlights current strategies to exploit the process in cancer therapy.
\end{abstract}

\section{Introduction}

Genome instability represents an enabling characteristic underlying the acquisition of the hallmarks of cancer [1]. Mammalian cells have evolved a variety of mechanisms to remove defective and genomically unstable cells. Mitotic catastrophe is a regulated antiproliferative process that occurs during defective or failed mitosis. Although it does not constitute a bona fide cell death mechanism in itself, mitotic catastrophe precedes and uses antiproliferative measures including apoptosis, necrosis, and senescence to prevent the proliferation of defective mitotic cells [2,3]. Mitotic catastrophe is characterised by unique nuclear alterations that lead to multinucleation and/or micronucleation and are used as morphological markers for detection. Giant multinucleated cells arise from clusters of missegregated uncondensed chromosomes, whereas micronucleated cells arise from lagging chromosomes or chromosome fragments during anaphase that are left outside the daughter nuclei formed during telophase, thereby giving rise to a micronucleus in addition to the main nucleus [4]. Figure 1 illustrates the morphological features following normal cell division (a) and a multinucleated cell formed during mitotic catastrophe (b). Failure of the mitotic catastrophe antiproliferative process leads to persistent genome instability and aneuploidy (c-f). Furthermore, as a result of the various antiproliferative pathways adopted by mitotic catastrophe it is often accompanied by morphological and biochemical features of apoptosis and necrosis $[2,3]$.

The detection and removal of mitotically defective cells are important steps in the prevention of genome instability. Defective or failed mitosis leads to the generation of aneuploid or tetraploid cells, which are a common feature of tumour cells $[5,6]$. It was postulated by Theodor Boveri more than 100 year ago that abnormality in chromosome segregation during mitosis could promote tumour formation [7]. It is now known that aneuploidy is present in approximately $90 \%$ of solid human tumours and $>50 \%$ of haematopoietic cancer [8]. Some aneuploid tumours have a minor imbalance in chromosome number whereas others are characterised by a large amount of aneuploidy and contain a near tetraploid chromosome number [5]. During mitosis, the loss or gain of chromosomes can occur through a variety of mechanisms including mitotic checkpoints defects, chromosome cohesion defects that lead to sister chromatid missegregation, and centrosome amplification that promotes multipolar mitosis. The hyperstabilisation of kinetochore-microtubule attachments can also prevent the correction of previous attachment defects [5]. On the other hand, tetraploid cells have twice the normal 


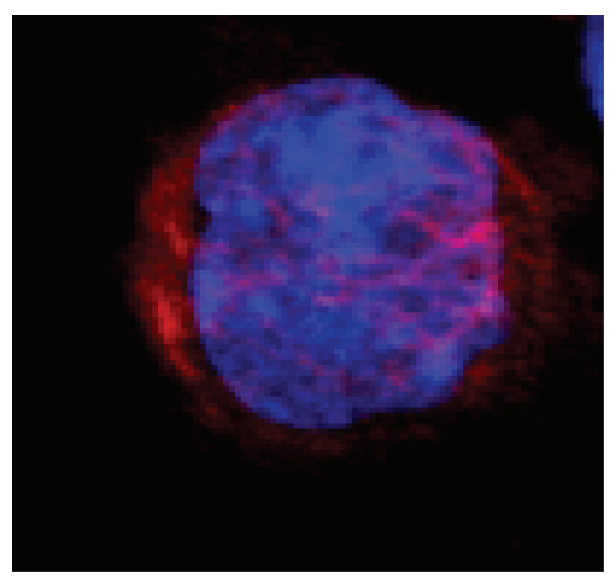

(a)

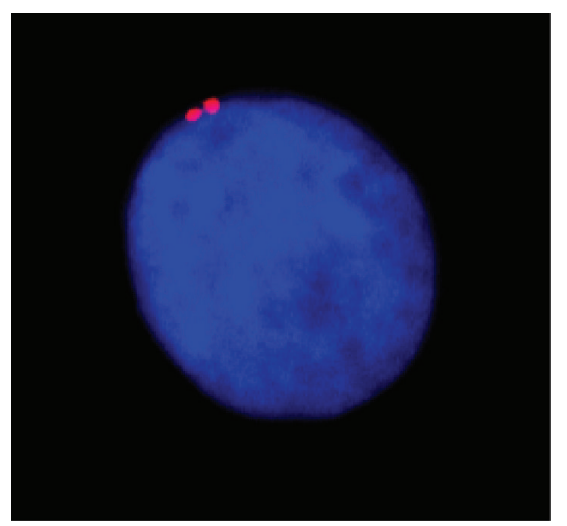

(c)

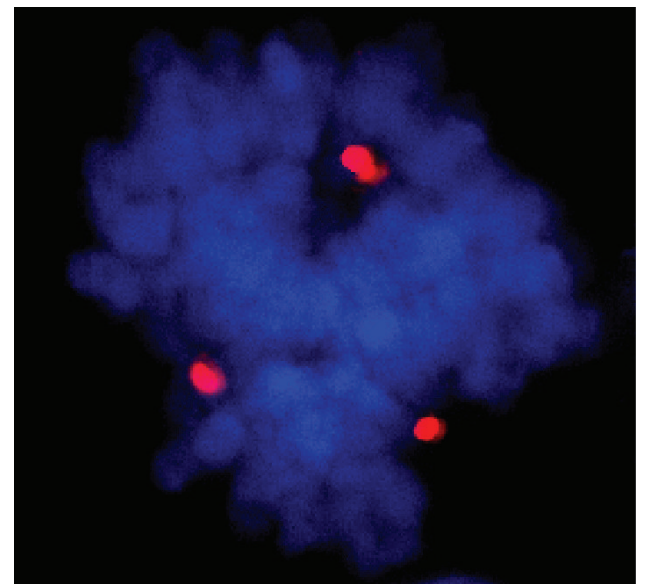

(e)

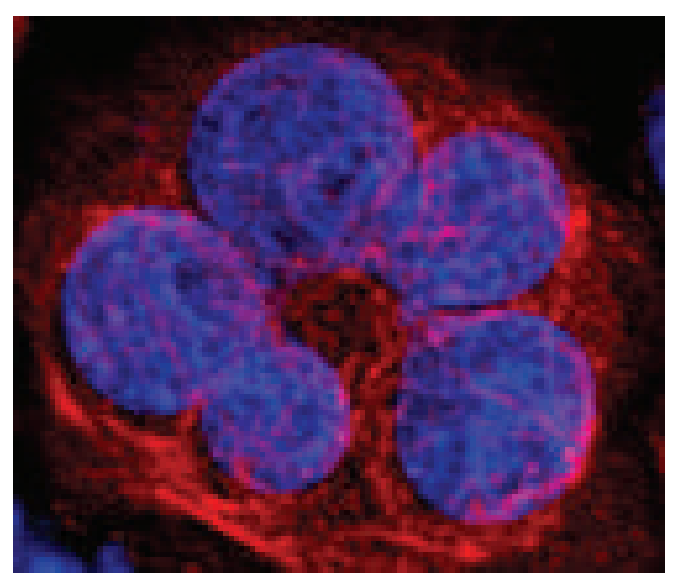

(b)

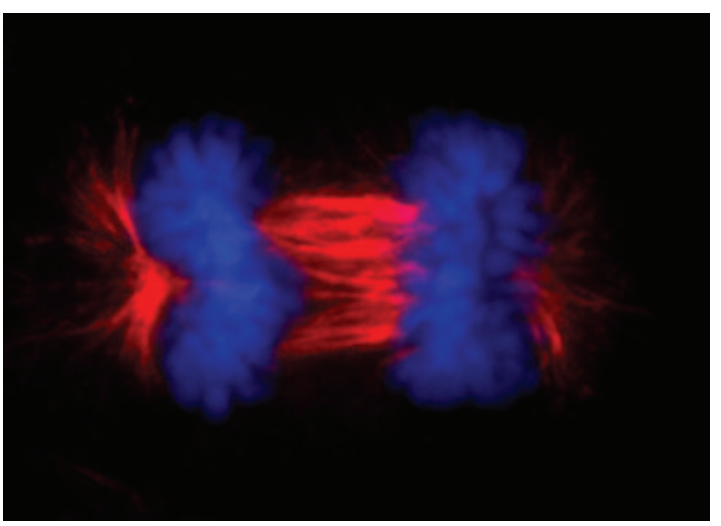

(d)

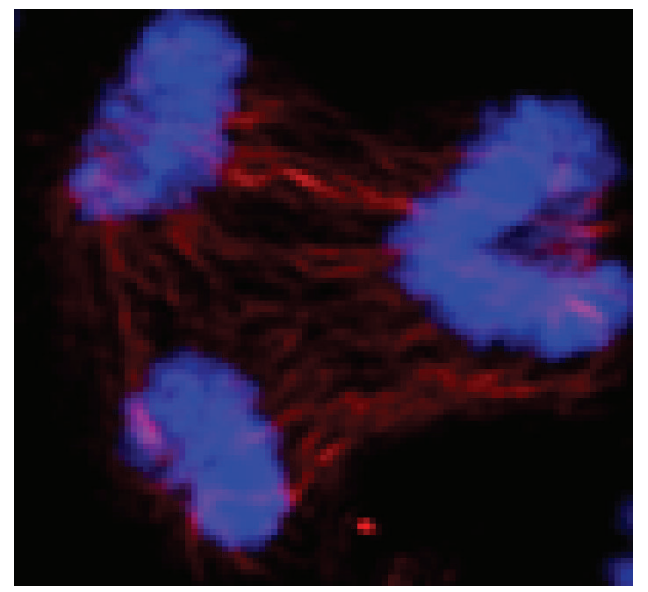

(f)

FIGURE 1: Morphological features of mitotic catastrophe. Human K562 chronic myeloid leukaemia cells during normal interphase (a) and a giant multinucleated cell following mitotic catastrophe induced by microtubule disruption (b). Interphase cell with two centrosomes (c) and normal chromosome segregation during anaphase (d). A cell containing $>2$ centrosomes (e) forms multipolar mitotic spindles (f) leading to aneuploidy as a result of mitotic catastrophe failure. DNA (blue), $\alpha$-tubulin (red) (a, b, d, f), and centrosome (red pericentrin staining) (c and e).

diploid chromosome content, which can arise due to mitotic slippage, cytokinesis failure, cell fusion, and endoreplication [5]. Tetraploid cells also contain twice the normal centrosome content, which promotes multipolar mitosis and whole chromosome missegregation, and provides a mechanism for the transition of cells from a tetraploid state to an aneuploid 
state. Multipolar mitotic divisions generally lead to catastrophic chromosome missegregation events that are incompatible with survival; however, cancer cells can avoid such catastrophic events and suppress multipolar mitosis by clustering centrosomes into two groups thereby allowing division to occur in a bipolar fashion [9].

While there has been much debate over the role of aneuploidy and tetraploidy in tumour onset, mounting evidence suggests that tetraploid cells can trigger cellular transformation and tumour formation $[5,6]$. For example, p53-/- tetraploid mouse cells formed tumours when transplanted into immunocompromised mice, which was not detected with the isogenic diploid cells [10]. Tetraploid cells generated by virus induced cell-cell fusion can proliferate and induce transformation [11, 12]. Mutation of adenomatous polyposis coli (APC) in colorectal cancer resulted in tetraploid genomes in vivo due to cytokinesis failure [13]. Furthermore, tetraploidy was identified as an early event during cervical carcinoma [14], and tetraploid cells formed following cytokinesis failure induced transformation in vivo $[15,16]$. In these cases transformation was coupled with extensive genome instability with abnormalities in the number and structure of chromosomes, providing evidence that tetraploidy represents an intermediate stage to promote aneuploidy and genome instability. Moreover, the loss of two tumour suppressor genes Breast Cancer Susceptibility Gene 2 (BRCA2) or the LATS1 tumour suppressor is accompanied by cytokinesis defects, suggesting a role for these tumour suppressors during cytokinesis [17, $18]$.

Aneuploidy increases the rate of both spontaneous and carcinogen-induced tumour formation; however, paradoxically, cases where aneuploidy does not promote tumourigenesis or where it suppresses tumourigenesis have also been reported [19]. It is clear that aneuploidy alters the path of tumour development, and a variety of factors influence the final outcome including the combination of chromosomes involved, cell type, genetic context, for example, the presence of additional cooperating mutations in key regulatory genes, as well as the microenvironment within different tissue [19]. This context driven outcome is illustrated in patients with Down syndrome who carry an extra copy of chromosome 21 and have increased incidence of haematological malignancies but reduced incidence of solid tumours [20, 21]. More recently it was suggested that the rate of chromosome missegregation will determine whether aneuploidy will promote or suppress tumour growth, where low rates of chromosome missegregation can promote tumourigenesis, and high rates lead to cell death and thereby prevent tumour growth [22]. In each scenario, the final outcome will be influenced by the functional status of damage sensing mitotic catastrophe signals as well as the cell survival and death machinery. Thus, mitotic catastrophe represents an important part of our genome maintenance machinery and abrogated or compromised signals will contribute to tumour onset. Understanding the molecular mechanism that dictates mitotic catastrophe has important implications for tumour prevention and treatment. Here we provide an update on current knowledge about the mechanism of mitotic catastrophe induction and signalling and highlight approaches to target and exploit the process in cancer treatment.

\section{Mitosis}

The cell cycle represents a highly coordinated process whereby a cell is divided into two genetically identical daughter cells. Pioneering work over the past four decades has revealed the molecular components that control the cell cycle in eukaryotes [23]. The mammalian cell cycle can be divided into distinct phases, DNA replication (Synthesis (S) phase) and division (Mitosis (M) phase), which are separated by Gap phases (G1 and G2). Mitosis is subdivided into prophase, prometaphase, metaphase, anaphase, telophase and cytokinesis, which together regulate nuclear envelope breakdown, chromosome attachment to spindle microtubules, alignment along the metaphase plate, sister chromatid separation, and finally, the coordinated plasma membrane remodelling and cytoplasmic division to produce two daughter cells [23]. Transition through the cell cycle is controlled by the interplay between cyclin-dependent kinases (cdks) and their respective cyclin binding partners $[23,24]$. Activation of cdk1, which occurs upon formation of a cdk1/cyclin B complex, regulates entry and progression through mitosis. Active cdk1/cyclin B phosphorylates substrates involved in nuclear envelope breakdown, assembly of the mitotic spindle, chromosome condensation, and activation of the spindle assembly checkpoint $[23,24]$. During metaphase the mitotic chromosomes, which are composed of sister chromatids held together by cohesion, are aligned on the mitotic spindle by stable microtubule attachment through their kinetochores. Properly aligned chromosomes are separated during anaphase and move towards opposite ends of the spindle [25]. A narrow region of overlapping nonkinetochore microtubules forms the central spindle at the midzone between separating chromosomes. This is followed by formation of centralspindlin comprised of MKLP1 and CYK4 and containing a GTPaseactivating protein (GAP) domain, and the Chromosomal Passenger Complex (CPC) composed of Aurora B and three additional proteins, INCENP, Survivn, and Borealin that are required for Aurora B regulation [26-29]. Central spindle recruits Ect2, a RhoGTPase leading to RhoA activation and assembly of an actinomyosin contractile ring around the central core of the cell. The contractile ring constricts to form a cleavage furrow that ingresses and packs the midzone microtubules to form the dense region termed the midbody at the centre of a long intercellular bridge holding daughter cells together. During cytokinesis, the midbody acts as a platform for components required during abscission of the plasma membrane and eventual daughter cell separation [26-29].

\section{The Spindle Assembly Checkpoint}

As well as the coordinated activation and inactivation of cdk1 that controls mitotic progression, the fidelity of the process is maintained by an independent and evolutionary conserved checkpoint known as the spindle assembly checkpoint (SAC) [25]. The SAC is a surveillance process at the transition from 


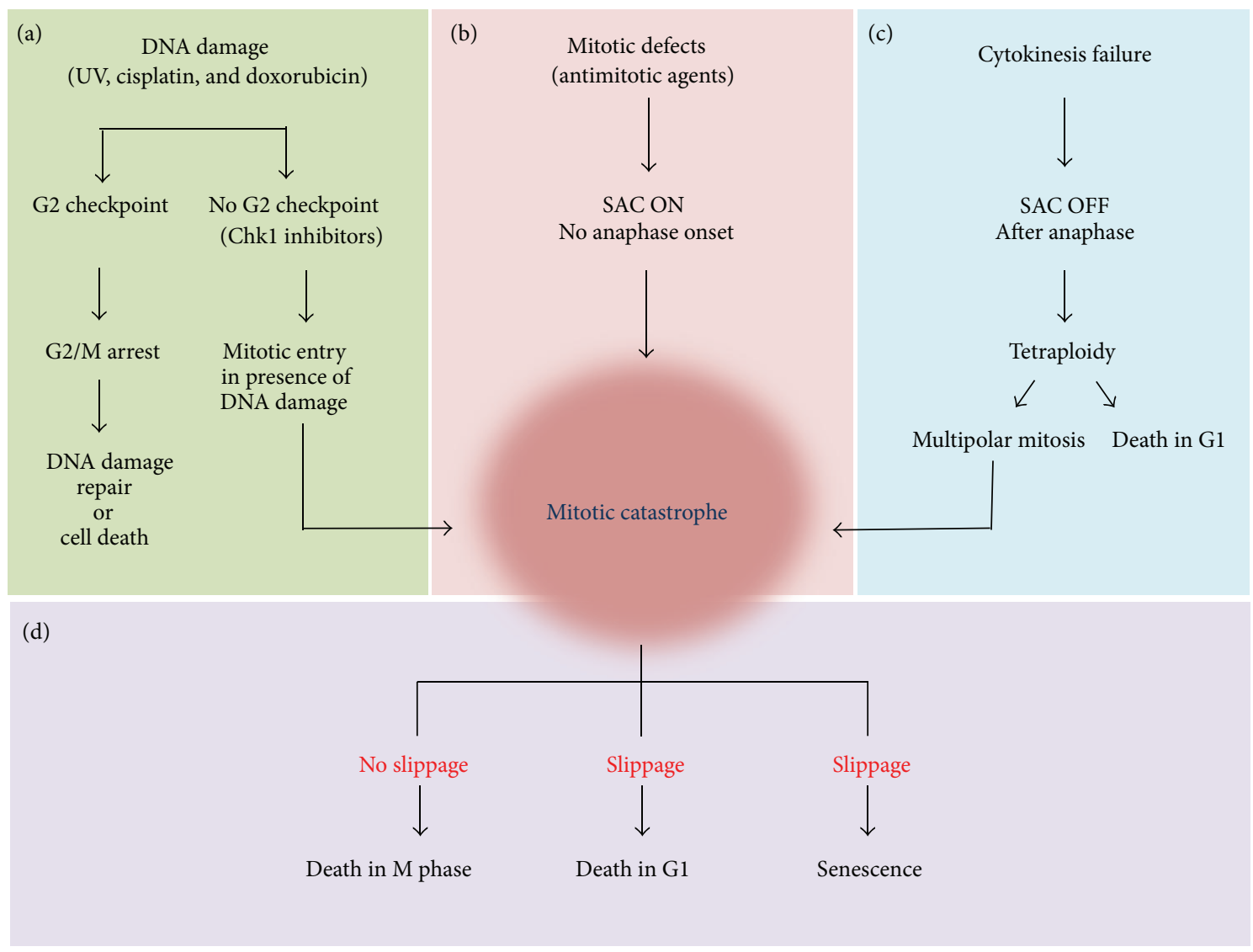

Figure 2: Mechanisms of mitotic catastrophe. (a) Cells with an abrogated G2 checkpoint will enter mitosis prematurely in the presence of damaged DNA and undergo segregation defects leading to mitotic catastrophe. (b) Cells with defects in mitotic apparatus and/or machinery required for faithful chromosome segregation fail to satisfy the spindle assembly checkpoint (SAC) and undergo prolonged mitotic arrest and mitotic catastrophe. (c) Cytokinesis defects that occur after anaphase will lead to a tetraploid progeny that will undergo mitotic catastrophe in the next M-phase. (d). Following activation of mitotic catastrophe, cells arrested in mitosis have three fates; they will undergo death in mitosis in the presence of cyclin B, or cyclin B levels will gradually fall allowing the cells to undergo slippage and exit mitosis where they subsequently undergo death in G1. Alternatively, cells can undergo senescence following slippage.

metaphase to anaphase that monitors the attachment of chromosomes to the kinetochore spindles and halts progression of anaphase until all chromosomes are correctly attached to the bipolar spindle [25]. Upon proper attachment, the SAC is switched off and Cdc20 activates the E3 ubiquitin ligase, Anaphase Promoting Complex (APC), leading to ubiquitination and proteolytic degradation of two substrates, cyclin B, which maintains cdk1 in an active form, and securin, which inhibits separase. Following degradation of securin, the liberated separase targets cohesion causing sister chromatid separation, and, anaphase onset. Furthermore, APC-mediated degradation of cyclin B leads to inactivation of cdk1 and signals mitotic exit [25]. Thus, the SAC is active for a short time during a normal mitosis. A single unattached or incorrectly attached chromosome is sufficient to block progression to anaphase by inhibition of APC activity, thereby leading to mitotic arrest.

\section{Mechanism of Mitotic Catastrophe}

Mitotic catastrophe senses mitotic damage and directs the defective cell to one of three possible antiproliferative fates
(Figure 2). Defective mitotic cells can engage the cell death machinery and undergo death in mitosis, when cyclin B levels remain high. Alternatively, defective cells can exit mitosis, known as slippage, and undergo cell death execution during $\mathrm{Gl}$ in the subsequent cell cycle. Finally, defective cells can exit mitosis and undergo senescence $[2,3]$. It is clear that mitotic catastrophe is always accompanied by mitotic arrest; however, the mechanisms that dictate cell fate following mitotic catastrophe remain unclear $[2,3]$. It was originally proposed that death signals gradually accumulate during mitotic arrest, and therefore the length of mitotic arrest determines cell fate [30]. Since then a model has been proposed whereby cell fate is dictated by two independent, yet competing networks; one involves activation of prodeath signals and the other protects against cyclin B degradation. Both pathways work in opposite directions during prolonged mitosis; that is, cell death signals accumulate and cyclin B levels decline. Both pathways have a threshold and the fate of the cell is determined by which threshold is breached first [31]. It is known that cyclin B levels slowly decline during prolonged mitotic arrest even in presence of an active SAC [32]; thus, if levels fall below 
the threshold that dictates mitotic exit, slippage occurs, whereas if the death threshold is met first the cell will undergo death in mitosis. Additional work has focused on determining the molecular events that govern each network and its threshold in order to understand how cells respond to mitotic stress [33].

The activity of the Bcl-2 protein family is a key determinant of fate following mitotic catastrophe [67-71] and phosphorylation mediated by cdk1 is an important signal that controls Bcl-2 family activity $[67,68,72,73]$. The family is comprised of multidomain prosurvival proteins $\left(\mathrm{Bcl}-2, \mathrm{Bcl}^{-}{ }_{\mathrm{XL}}\right.$, $\mathrm{Bcl}_{-}{ }_{\mathrm{W}}, \mathrm{Mcll}, \mathrm{Al}$, and Bcl-B) and multidomain proapoptotic effector proteins (Bax, Bak, and Bok) as well as BH3-only proteins (Bim, PUMA, Bad, NOXA, Bik, Hrk, Bmf, and tBid) [74]. The multidomain members of the family (the prosurvival proteins and the effectors Bak, Bax, and Bok) contain four BCL-2 homology regions (BH1-BH4), whereas the $\mathrm{BH} 3$-only proteins contain only a $\mathrm{BH} 3$ domain, which is important in mediating their interaction with the multidomain members. Various models are proposed to describe how prosurvival and proapoptotic $\mathrm{Bcl}-2$ proteins interact together to control apoptosis. For a recent review see [74].

$\mathrm{Bcl}-2$ proteins are also regulated in a transcriptional and posttranslational manner. Active cyclin $\mathrm{B} / \mathrm{cdk} 1$ directly phosphorylates $\mathrm{Bcl}-2, \mathrm{Bcl}_{-\mathrm{XL}}$, and $\mathrm{Mcl}-1$ during mitosis and negatively regulates their activity $[67,68]$. Cdk1 phosphorylation of $\mathrm{Bcl}-2$ and $\mathrm{Bcl}_{-\mathrm{XL}}$ blocks heterodimer formation with proapoptotic members, Bax and Bak, promoting their oligomerization at the outer mitochondrial membrane, release of cytochrome $\mathrm{C}$, and thereby apoptosis $[75,76]$. In contrast, cdkl-mediated phosphorylation of Mcl-1 during mitosis controls protein stability by ubiquitination and degradation via the proteasome. Harley et al. [68] demonstrated that phosphorylation of Mcl-1 by $\mathrm{cdk} 1 /$ cyclin B initiates its degradation during mitotic arrest in a Cdc20/APC-3 dependent manner. Like Bcl-2 and $\mathrm{Bcl}_{-\mathrm{XL}}$, loss of antiapoptotic Mcl-1 promotes the oligomerisation of Bax and Bak and thus death during prolonged mitotic arrest. Thus, it is proposed that during a typical mitosis the transient phosphorylation of Mcl-1 by cdk1/cyclin B is not sufficient to drive cell death before cyclin B levels drop sufficiently to inactive cdkl. This transient effect ensures that normal cells are not subject to a fate of apoptosis during normal mitosis. In contrast, however, the sustained cdkl activity that occurs during mitotic arrest leads to a significant drop in Mcl-1 levels thereby suppressing its antiapoptotic effect and triggering cell death before mitotic exit. Phosphorylation of Mcl-1 also controls interaction with the FBW7 tumour-suppressor and subsequent degradation by the skp-cullin-F-box (SCF) complex during mitotic arrest [77]. Collectively, these reports highlight a role for posttranslational phosphorylation and ubiquitination in the crosstalk between the mitotic and apoptotic machinery to control cell fate during mitotic arrest.

The BH3-only protein Bim undergoes cdk-1-mediated phosphorylation during mitosis. Mac Fhearraigh and Mc Gee [72] demonstrated that two Bim isoforms, $\mathrm{Bim}_{\mathrm{EL}}$ and $\mathrm{Bim}_{\mathrm{L}}$, undergo transient phosphorylation during normal mitosis; however, hyperphosphorylation was evident during sustained mitotic arrest. Furthermore, Bim directly binds cyclin
$\mathrm{B}$, which acts as a molecular bridge for cdk1 phosphorylation, and serine 44 within Bim $_{\mathrm{L}}$ was identified as a novel cdk-1 phosphorylation site [72]. It is suggested that cdk-1-mediated phosphorylation of Bim alters its heterodimer formation with $\mathrm{Bcl}-2$, leading to enhanced activation of Bak and mitochondrial cell death [75], consistent with the view that mitochondrial proapoptotic signalling entails the interplay between pro- and antiapoptotic Bcl-2 proteins [78]. In contrast, cdk1dependent phosphorylation of $\mathrm{Bim}_{\mathrm{EL}}$ promotes its polyubiquitylation and degradation via the proteasome during mitotic arrest [73]. Thus, based on the competing model that was proposed by Gascoigne and Taylor, [31] the gradual loss of cyclin B during prolonged mitotic arrest will lead to the loss of cdk-1-mediated Bim phosphorylation, which will alter its cell death activity during prolonged mitosis and following slippage, either through stability or heterodimer formation. This may partially explain the contradictory reports that mitotic catastrophe-induced death occurs via Bim-dependent and Bim-independent mechanisms [79-82].

Cdk1 also phosphorylates members of the proteolytic caspase family, specifically caspase-2, caspase-8, and caspase9 , leading to inhibition of their apoptotic activity, which is believed to be a cytoprotective measure during normal mitosis [83-85]. Furthermore, caspase activity is not required for spindle assembly checkpoint function or mitotic slippage following mitotic catastrophe [86]; however, the downstream cell death can manifest in a caspase-dependent or caspaseindependent manner [3]. Cell death can involve mitochondrial perturbations including mitochondrial outer membrane permeabilisation (MOMP) and cytochrome $\mathrm{C}$ release induced following Bax/Bak oligomerisation and pore formation on the outer mitochondrial membrane, leading to caspase-dependent apoptosis [87]. Alternatively cell death can occur through the Permeability Transition Pore Complex (PTPC), a large complex that bridges the junction between the inner and outer mitochondrial membranes. A sudden increase in permeability of the inner mitochondrial membrane to small solutes leads to $\mathrm{Ca}^{2+}$ overload, oxidative stress, and Mitochondrial Permeability Transition- (MPT-) induced death that is independent of caspase activity [88]. Although details of the mitotic and cell death processes are well characterised, the molecular signals that link these events during mitotic catastrophe remain poorly understood and are the focus of intense investigation. Two interesting candidates are Mad2 and survivin that are reported to have dual functions in regulating spindle checkpoint and cell death $[58,89]$. Furthermore, it was recently shown that mitochondrial Protein Tyrosine Phosphatase 1B (PTP1B) undergoes coordinate phosphorylation by cdk1 and plk1 during mitotic arrest. Phosphorylation of mitochondrial PTP1B increases its phosphatase activity and sensitises cells to antimitotic agents [90] representing a new molecular link between the mitotic machinery and the mitochondrion during mitotic catastrophe. The identification of PTP1B substrates at the mitochondria will provide better insight into its precise function and help delineate the downstream execution events. It was also recently demonstrated that cdkl can directly phosphorylate and regulate numerous mitochondrial proteins, including subunits of the respiratory chain to regulate respiration in 
a cell cycle specific manner [91, 92], providing a further link between cdk1 activity and mitochondrial function. It remains to be determined how mitochondrial energetics are altered during mitotic catastrophe.

\section{Induction of Mitotic Catastrophe by Mitotic Perturbations}

Faithful mitotic progression requires the proper function of various cell components including microtubules, mitotic enzymes, motor proteins, and protein complexes [34, 93]. Microtubules are essential cytoskeletal components composed of subunits of $\alpha$-tubulin and $\beta$-tubulin that dimerise to form linear protofilaments, which together form microtubules. The dynamic nature of microtubule plus ends, which undergo continuous polymerisation and depolymerisation, allow them to form cell structure and enable motility and intracellular transport [93]. During mitosis microtubules form a bipolar spindle array that emanates from the centrosomes located at opposite sides of the cell. The dynamic nature of microtubule ends facilitates proper attachment to chromosomes at their kinetochore [25]. Unattached or incorrectly attached kinetochores, such as merotelic or syntelic attachments, initiate a network of signals to recruit mitotic checkpoint components including Mad1, Mad2, Bub1, Bub3, BubR1, CENP-E, and Mps1 to kinetochores [25, 94-96]. The formation of an inhibitory complex termed the mitotic checkpoint complex (MCC), consisting of three SAC components, Mad2, BubR1, and Bub3 as well as Cdc20, acts as the SAC effector that is enriched at unattached kinetochores. MCC binds to and potently inhibits APC by sequestering Cdc20, thereby preventing mitotic exit [25, 94-96] (Figure 2). Biorientated attachment of all sister chromatid pairs to their kinetochore microtubules promotes displacement of the SAC proteins, allowing release of Cdc20 from the MCC. Released $\mathrm{Cdc} 20$ can then activate the APC and promote mitotic exit. Improper kinetochore-microtubule attachment also causes reduced tension across the spindle apparatus which inhibits the APC through a mechanism involving Aurora B kinase $[97,98]$.

Most cancer cells display a certain level of aneuploidy $[5,6,19]$, and it was proposed that mechanisms that induce additional instability constitute a therapeutic strategy. Consistent with that, cancer cells are more susceptible to cell death following mitotic damage in comparison to nontransformed cells [99], and a number of mitotic targets have been identified. These include mitotic kinases such as aurora kinases, monopolar spindle 1 (Mps1), and polo-like kinases (Plks) that play key roles during faithful chromosome segregation [100]. The aurora kinase family of serine/threonine protein kinases includes Aurora A, Aurora B and Aurora C, each with a distinct expression pattern, subcellular localisation pattern, and function [101, 102]. Aurora A localises to centrosomes during interphase and to spindles poles and spindle microtubules during mitosis, where it regulates mitotic entry, centrosome maturation, and spindle formation [35]. Aurora B localises to kinetochores and forms part of the Chromosome Passenger
Complex that plays critical roles during chromosome condensation, biorientation, and cytokinesis [97]. Thus, Aurora $\mathrm{A}$ and Aurora B act at different stages of mitosis. Aurora C is mainly expressed in testes and required for spermatogenesis and mouse embryogenesis [35]. Dysregulated aurora kinase activity generates mitotic abnormalities and cytokinesis failure $[103,104]$. Thus, the critical role of aurora kinases during mitosis makes them indispensible with faithful mitosis.

Mpsl forms a core component of the spindle assembly checkpoint (SAC) and functions in the alignment and orientation of chromosomes during metaphase [105]. Polo-like kinases (Plks) also play critical roles during mitotic progression $[102,106]$. Five members of the Plk family have been identified in humans. The most widely studied is Plk1, which is involved in assembly of the mitotic spindle, maturation of centrosomes, activation of the SAC, chromosome segregation, and cytokinesis $[102,106]$. Deregulation of the centrosome cycle leading to supernumerary centrosomes generates multipolar mitosis that promotes genome instability, SAC activation, and mitotic catastrophe $[107,108]$.

Faithful mitosis is also dependent on microtubule motor proteins such as Eg5, a plus-end directed motor from the kinesin superfamily that is responsible for mitotic spindle formation and function. Disruption of Eg5 function during mitosis leads to monopolar spindles and activation of the SAC. Furthermore, the centromere-associated motor protein (CENP-E) is a component of the kinetochore corona fibres of mammalian centromeres and is required for chromosome biorientated attachment and proper mitotic checkpoint signalling [109-111]. In addition to disrupting chromosome segregation, inhibition of cytoplasmic division following anaphase onset will generate genome instability and stimulate mitotic catastrophe in the next cell cycle $[109,112]$ (Figure 2). The development of pharmacological agents that induce mitotic catastrophe via disruption of bipolar spindle function or faithful chromosome segregation is discussed in more details later.

\section{Induction of Mitotic Catastrophe following DNA Damage}

DNA damage induced by intrinsic or extrinsic factors threatens genome integrity and stability. Failure to repair the DNA damage leads to mutations and genome instability that ultimately contributes to diseases including cancer $[113,114]$. The DNA Damage Response (DDR) is a complex mechanism to sense various types of DNA damage and respond appropriately to maintain genomic integrity. Following DNA damage the phosphatidylinositol 3-kinase-related kinases ATM (ataxia-telangiectasia mutated) and ATR (ATM and Rad-3 related) are activated and coordinate activation of the DNA damage checkpoints through the phosphorylation of numerous downstream substrates. Checkpoint kinase-1 (Chk1) and checkpoint kinase-2 (Chk2) are serine threonine kinases that transduce the DNA damage signal downstream. Chk2, which is expressed throughout the cell cycle, undergoes phosphorylation and activation by ATM, whereas Chk1 is preferentially 
expressed in S and G2 and is phosphorylated by ATR. In addition to Chk1 and Chk2, MAPK-activated protein kinase-2 (MK2) regulates cell cycle checkpoint activation [113, 114]. Genomic stress activates the G1 checkpoint, which prevents $S$ phase entry by inhibition of DNA replication. At this point, Chk2, which is activated by ATM, phosphorylates and suppresses the phosphatase Cdc25-A, thereby preventing activation of cyclin E/cdk2 and thus halting the cell cycle. The $\mathrm{S}$ phase checkpoint is activated in response to replication errors and DNA damage that occurs during $S$ phase, whereas the G2 checkpoint deals with cells that have either undergone DNA damage in G2, or they have escaped the G1 and S phase checkpoints. Cdk1 activity and mitotic entry are tightly regulated and balanced by inactivating phosphorylation by the protein kinases WEE1 and myelin transcription factor 1 (MYT1), together with the activating Cdc25 phosphatase. Thus, WEE1 and Cdc25 act as a central switch for mitosis and are regulated by posttranslational alterations thereby enabling rapid switching. At G2, Chk1, which is activated by ATR, phosphorylates and suppresses Cdc25-A, -B, and - $\mathrm{C}$ thereby preventing cyclin $\mathrm{B} / \mathrm{cdk} 1$ activation and causing G2 arrest [113-115]. G2 arrest is also initiated by MK2 which inactivates Cdc25-B and -C [113]. Thus, the G2 checkpoint is the last opportunity to halt the cycle and repair DNA damage in cells that have escaped the G1 and S phase checkpoints. Abrogated or compromised G2 checkpoint will allow premature mitotic entry of defective cells that fail to undergo proper chromosome segregation thereby leading to mitotic catastrophe (Figure 2). In support of this, the fusion of interphase and mitotic cells led to mitotic catastrophe which was due to the cyclin $\mathrm{B} / \mathrm{cdk} 1$ driven-premature entry of cells into mitosis before they had completed S or G2 [116]. Furthermore, knockout of the cytoplasmic binding protein 14-3-3 $\sigma$ in colorectal cancer cells resulted in failure to sequester cyclin B1 and prevented G2 arrest following DNA damage, culminating in mitotic catastrophe [117]. Inhibition of Chk2 also abrogates the G2 checkpoint leading to mitotic catastrophe following DNA damage. [118]. In contrast, cells that harbour DNA damage and undergo death in interphase do not constitute an example of mitotic catastrophe $[2,3,113]$. Furthermore, while an abrogated or defective G2 checkpoint is essential for DNA damage-induced mitotic catastrophe, the eventual mode of cell death induced is determined by whether p53 is present or absent. For example, DNA damage induces two distinct forms of cell death in ovarian carcinoma [119]. Functional p53 triggered apoptosis in ovarian carcinoma cells following mitotic catastrophe whereas loss of p53 in these cells triggered necrosis. The exact mechanism of p53 activation during or after mitotic catastrophe remains to be elucidated; however, it was shown that phosphorylated H2AX-ATM-p53 pathway dictates an apoptotic outcome following mitotic catastrophe. Loss of p53 or depletion of ATM protected against apoptosis and instead led to necrosis [4]. Apoptosis driven by p53 is also associated with caspase activity [120]. Thus it is proposed that the initiation of mitotic catastrophe occurs independently of p53 status and caspase activity; however, the presence of functional p53 is required for a caspase-mediated apoptotic response.
TABLE 1: Exploiting mitotic catastrophe in cancer therapy.

\begin{tabular}{|c|c|c|}
\hline Mechanism of action & Inducer & References \\
\hline \multicolumn{3}{|l|}{$\begin{array}{l}\text { Microtubule targeting } \\
\text { agents }\end{array}$} \\
\hline $\begin{array}{l}\text { Microtubule } \\
\text { polymerisers }\end{array}$ & Taxanes & \multirow[b]{2}{*}[34]{} \\
\hline $\begin{array}{l}\text { Microtubule } \\
\text { depolymerisers }\end{array}$ & Vinca alkaloids & \\
\hline \multicolumn{3}{|l|}{$\begin{array}{l}\text { Non-microtubule } \\
\text { antimitotic agents }\end{array}$} \\
\hline \multirow{4}{*}{$\begin{array}{l}\text { Mitotic spindle } \\
\text { targets }\end{array}$} & $\begin{array}{c}\text { Aurora kinase } \\
\text { inhibitors } \\
\text { Alisertib }\end{array}$ & {$[35,36]$} \\
\hline & $\begin{array}{c}\text { KSP inhibitors } \\
\text { Eg5 } \\
\text { AZD } 4877 \\
\text { Ispinesib } \\
\text { ARRY-520 }\end{array}$ & {$[37-42]$} \\
\hline & $\begin{array}{l}\text { CENP-E inhibitors } \\
\text { GSK923295 }\end{array}$ & {$[43,44]$} \\
\hline & $\begin{array}{c}\text { PLK-1 inhibitors } \\
\text { B12536 }\end{array}$ & [45-47] \\
\hline $\begin{array}{l}\text { Mitotic checkpoint } \\
\text { targets }\end{array}$ & $\begin{array}{l}\text { MPS1 inhibitors } \\
\text { NMS-P715 } \\
\text { MPS1-IN-3 }\end{array}$ & {$[48-51]$} \\
\hline $\begin{array}{l}\text { Mitotic exit } \\
\text { inhibition }\end{array}$ & $\begin{array}{c}\text { APC inhibitor } \\
\text { TAME }\end{array}$ & [52-54] \\
\hline $\begin{array}{l}\text { Centrosome } \\
\text { disruption }\end{array}$ & Griseofulvin & [55-57] \\
\hline \multirow{2}{*}{$\begin{array}{l}\text { G2 checkpoint } \\
\text { abrogation }\end{array}$} & $\begin{array}{c}\text { Chk1 inhibitors } \\
U C N-01 \\
A Z D 7762\end{array}$ & [58-63] \\
\hline & $\begin{array}{c}\text { HDAC inhibition } \\
\text { Trichostatin A }\end{array}$ & [64-66] \\
\hline
\end{tabular}

\section{Exploiting Mitotic Catastrophe in Cancer Therapy}

Mitotic catastrophe is induced by a variety of agents classified as those that disrupt mitotic progression or directly damage DNA (Figure 2 and Table 1). The best known antimitotic agents are the microtubule targeting agents (MTAs), also known as spindle poisons [34]. MTAs are grouped into two families: the microtubule polymerisers which include the taxanes (paclitaxel and docetaxel) and the microtubule depolymerisers which include the vinca alkaloids (vinblastine and vincristine). The suppression of microtubule dynamics by both groups precludes normal bipolar spindle formation and prevents chromosome biorientation, leading to mitotic arrest and cell death. Taxol (paclitaxel) originally isolated in 1967 from a Yew tree (Taxus brevifolia), was approved for clinical use in 1995 and is widely used across a range of malignancies. For example, taxanes have been used in the treatment of Kaposi's sarcoma, non-small-cell lung cancer, breast cancer, ovarian cancer, and prostate cancer, whereas vinca alkaloids are used to treat haematological malignancies $[34,121]$. Although they have been used clinically for decades, 
microtubule targeting agents lack specificity towards cancer cells and disrupt other important microtubule-dependent functions leading to severe side effects including neuropathy. Furthermore, the development of drug resistance limits their use, which can be ascribed to drug efflux pumps, overexpression of prosurvival $\mathrm{Bcl}-2$ proteins, and mutations in tubulin that abrogates drug binding $[122,123]$. Resistance may also occur as a result of mitotic slippage [32]. Thus, research efforts have focused on the development of non-microtubule antimitotic therapeutics, such as those targeted at mitotic kinases and spindle motor proteins, with the hope that that they would overcome some of the drawbacks associated with microtubule targeting agents.

Primary tumours frequently have overexpressed and/or amplified aurora kinases. Moreover, their depletion or inhibition impairs the proliferation of cancer cells, thus, making them an attractive target for cancer treatment $[35,36]$. A number of aurora kinase inhibitors have been developed that target the enzymes ATP binding domain. Early inhibitors did not display specificity towards a family member; however, in recent years work has focused on development of selective inhibitors and a number are in various stages of clinical evaluation including Alisertib (MLN8237) that has displayed promising antitumour properties and is currently in Phases I and II trials [35].

Mps1 is highly expressed in human tumours where it promotes cell proliferation [48]. Mps1 kinase inhibitors have been developed which induce mitotic defects and death in cancer cells, across a variety of preclinical models, either alone or in combination with microtubule inhibitors [49-51].

Plk1 is upregulated in a range of human tumours; thus targeting Plk1 is an attractive therapeutic strategy [45] and a number of inhibitors are under clinical evaluation including BI2536 [46, 47]. Furthermore, agents that disrupt the centrosome cycle in tumour cells, through centrosome amplification and centrosome declustering promote multipolar mitosis, genome instability, and mitotic catastrophe [55-57].

A number of kinesin motor protein inhibitors have been developed [37, 124]. Monastrol is a selective inhibitor of the kinesin-5 motor protein (KSP, also termed Eg5). Eg5 inhibition leads to mitotic arrest and death in tumour cells in culture and in xenograft models. Furthermore, they were found to be free from severe cytotoxic effects and are generally well tolerated [37]. Eg5 inhibitors under clinical development include AZD4877 [38], Ispinesib [39, 40], and ARRY-520 [41]. Eg5 inhibition is also effective in targeting taxol resistant cancers [42]. CENP-E (centrosome-associated protein-E) is a microtubule motor that plays a role in mitosis. The small molecule CENP-E inhibitor, GSK923295, induces defective mitosis and displays antiproliferative effects in vivo [43] and has recently entered clinical trial [44].

Cancer cells often harbour a deficient or defective G1 checkpoint due to aberrant p53 signalling, which ultimately leads to increased DNA damage at the G2 checkpoint compared to normal cells [125]. Based on this, the G2 checkpoint has emerged as an attractive anticancer target. Abrogation of the G2 checkpoint allows cells with unrepaired DNA damage to proceed into a premature $M$ phase [59]. Thus, cancer cells that are defective in G1 and G2 checkpoints will undergo mitotic catastrophe following DNA damage induced by radiation, alkylating agents, and doxorubicin [113]. The Chk1 kinase inhibitors, UCN-01 and AZD7762, abrogate the G2 checkpoint and potentiate death in p53-deficient tumours $[58,60,61]$ and are currently in clinical development $[62,63]$. Evaluation of a panel of therapeutic agents in combination with Chk1 inhibition highlights that the precise drug combinations are important and influence the outcome in a particular genetic background and when treating a certain tumour type [126]. In addition to Chk1, targeting WEE1 kinase activity together with DNA damage can effectively induce mitotic catastrophe [127]. Furthermore, histone deacetylase (HDAC) inhibitors promote mitotic catastrophe and cell death and have shown promise in multiple myeloma and glioma treatments [64-66].

Despite the promising preclinical data displayed by new generation antimitotic agents, their clinical efficacy has been disappointing in comparison to microtubule targeting agents $[37,128]$. This may be explained by the shorter doubling time of cells in culture compared to patients [128] and by differences in drug retention times [129]. It has also been suggested that the success of microtubule targeting agents may be due to nonmitotic function of microtubules [130]. Furthermore, the development of resistance to antimitotic agents represents a major challenge that occurs following mitotic slippage when defective cells adapt and survive [131], although in some cases mitotic slippage is required for cell death [132]. Based on this observation, recent research has focused on strategies to block slippage and mitotic exit in order to maximise mitotic arrest-induced death [37]. Such approaches include targeting APC-Cdc20 to prevent cyclin B degradation and mitotic exit that have shown a very promising response [52-54]. An alternative approach is the inhibition of cytokinesis which blocks mitotic exit in postanaphase cells and may be an attractive strategy to overcome resistance in slippage prone cells. Small molecule dynamin GTPase inhibitors have shown antiproliferative effects and induce cytokinesis failure and cell death in cancer cells [133].

It is clear that mitotic catastrophe is an important anticancer strategy that is achieved by a variety of mechanisms that target the cell cycle. Although these approaches target proteins that are upregulated in cancer cells, thereby providing a therapeutic window to preferentially kill the cancer cells, they are not specific to cancer cells and are likely to be accompanied by some side effects. Recent reports highlight that the myc oncogene regulates mitotic events to support its oncogenic program $[134,135]$ and one way that this may occur is through transcriptional regulation of aurora kinase expression $[136,137]$. Moreover, loss of myc activity due to inhibition of sumoylation [134] or transcriptional inactivation by omomyc [135] led to mitotic catastrophe and cell death in in vivo models of breast cancer and glioma, respectively. Thus, targeting myc activity, using approaches that inhibit sumoylation and/or mimic omomyc action, represents new approaches to selectively induce mitotic catastrophe in cancer cells. Furthermore, a better understanding of the postmitotic signals that connect to the cell death and senescence pathways will reveal new approaches to push cells down a defined antiproliferative route and is likely to synergise with current 
antimitotic drugs to kill cancer cells before adaption and the development of drug resistance. These new approaches may provide more effective strategies to exploit mitotic catastrophe in cancer prevention and treatment.

\section{Conflict of Interests}

The author declares that there is no conflict of interests regarding the publication of this paper.

\section{Acknowledgments}

Many thanks are due to Mr. Paul Lavin, UCD School of Biomolecular \& Biomedical Science, University College Dublin, and UCD Conway Imaging Core Technology for fluorescent imaging. The author acknowledges funding in the field from the Health Research Board of Ireland and Science Foundation Ireland.

\section{References}

[1] D. Hanahan and R. A. Weinberg, "Hallmarks of cancer: the next generation," Cell, vol. 144, no. 5, pp. 646-674, 2011.

[2] L. Galluzzi, I. Vitale, J. M. Abrams et al., "Molecular definitions of cell death subroutines: recommendations of the Nomenclature Committee on Cell Death 2012," Cell Death \& Differentiation, vol. 19, no. 1, pp. 107-120, 2012.

[3] I. Vitale, L. Galluzzi, M. Castedo, and G. Kroemer, "Mitotic catastrophe: a mechanism for avoiding genomic instability," Nature Reviews Molecular Cell Biology, vol. 12, no. 6, pp. 385392, 2011.

[4] G. Imreh, H. V. Norberg, S. Imreh, and B. Zhivotovsky, "Chromosomal breaks during mitotic catastrophe trigger $\gamma \mathrm{H} 2 \mathrm{AX}$ ATM-p53-mediated apoptosis," Journal of Cell Science, vol. 124, part 17, pp. 2951-2963, 2011.

[5] A. J. Holland and D. W. Cleveland, "Losing balance: the origin and impact of aneuploidy in cancer," The EMBO Reports, vol. 13, no. 6, pp. 501-514, 2012.

[6] D. J. Gordon, B. Resio, and D. Pellman, "Causes and consequences of aneuploidy in cancer," Nature Reviews Genetics, vol. 13, no. 3, pp. 189-203, 2012.

[7] T. Boveri, "Concerning the origin of malignant tumours by Theodor Boveri. Translated and annotated by Henry Harris," Journal of Cell Science, vol. 121, no. 1, pp. 1-84, 2008.

[8] F. Mitelman, B. Johansson, and F. E. Mertens, Mitelman Database of Chromosome Abberations and Gene Fusions in Cancer, Cancer Genome Anatomy Project, 2012, http://cgap.nci.nih .gov/Chromosomes/Mitelman.

[9] N. J. Quintyne, J. E. Reing, D. R. Hoffelder, S. M. Gollin, and W. S. Saunders, "Spindle multipolarity is prevented by centrosomal clustering," Science, vol. 307, no. 5706, pp. 127-129, 2005.

[10] T. Fujiwara, M. Bandi, M. Nitta, E. V. Ivanova, R. T. Bronson, and D. Pellman, "Cytokinesis failure generating tetraploids promotes tumorigenesis in p53-null cells," Nature, vol. 437, no. 7061, pp. 1043-1047, 2005.

[11] D. M. Duelli, S. Hearn, M. P. Myers, and Y. Lazebnik, "A primate virus generates transformed human cells by fusion," The Journal of Cell Biology, vol. 171, no. 3, pp. 493-503, 2005.

[12] D. M. Duelli, H. M. Padilla-Nash, D. Berman, K. M. Murphy, T. Ried, and Y. Lazebnik, "A virus causes cancer by inducing massive chromosomal instability through cell fusion," Current Biology, vol. 17, no. 5, pp. 431-437, 2007.

[13] C. M. Caldwell, R. A. Green, and K. B. Kaplan, "APC mutations lead to cytokinetic failures in vitro and tetraploid genotypes in Min mice," Journal of Cell Biology, vol. 178, no. 7, pp. 1109-1120, 2007.

[14] A. J. Olaharski, R. Sotelo, G. Solorza-Luna et al., “Tetraploidy and chromosomal instability are early events during cervical carcinogenesis," Carcinogenesis, vol. 27, no. 2, pp. 337-343, 2006.

[15] L. Lv, T. Zhang, Q. Yi et al., “Tetraploid cells from cytokinesis failure induce aneuploidy and spontaneous transformation of mouse ovarian surface epithelial cells," Cell Cycle, vol. 11, no. 15, pp. 2864-2875, 2012.

[16] G. Högnäs, S. Tuomi, S. Veltel et al., "Cytokinesis failure due to derailed integrin traffic induces aneuploidy and oncogenic transformation in vitro and in vivo," Oncogene, vol. 31, no. 31, pp. 3597-3606, 2012.

[17] M. J. Daniels, Y. Wang, M. Lee, and A. R. Venkitaraman, "Abnormal cytokinesis in cells deficient in the breast cancer susceptibility protein BRCA2," Science, vol. 306, no. 5697, pp. 876-879, 2004.

[18] X. Yang, K. Yu, Y. Hao et al., "LATS1 tumour suppressor affects cytokinesis by inhibiting LIMK1," Nature Cell Biology, vol. 6, no. 7, pp. 609-617, 2004.

[19] A. J. Holland and D. W. Cleveland, "Boveri revisited: chromosomal instability, aneuploidy and tumorigenesis," Nature Reviews Molecular Cell Biology, vol. 10, no. 7, pp. 478-487, 2009.

[20] H. Hasle, I. H. Clemmensen, and M. Mikkelsen, "Risks of leukaemia and solid tumours in individuals with Down's syndrome," The Lancet, vol. 355, no. 9199, pp. 165-169, 2000.

[21] D. Satgé, D. Sommelet, A. Geneix, M. Nishi, P. Malet, and M. Vekemans, "A tumor profile in Down syndrome," American Journal of Medical Genetics, vol. 78, no. 3, pp. 207-216, 1998.

[22] A. D. Silk, L. M. Zasadil, A. J. Holland, B. Vitre, D. W. Cleveland, and B. A. Weaver, "Chromosome missegregation rate predicts whether aneuploidy will promote or suppress tumors," Proceedings of the National Academy of Sciences of the United States of America, vol. 110, no. 44, pp. E4134-E4141, 2013.

[23] H. Hochegger, S. Takeda, and T. Hunt, "Cyclin-dependent kinases and cell-cycle transitions: does one fit all?" Nature Reviews Molecular Cell Biology, vol. 9, no. 11, pp. 910-916, 2008.

[24] M. Malumbres and M. Barbacid, "Mammalian cyclin-dependent kinases," Trends in Biochemical Sciences, vol. 30, no. 11, pp. 630-641, 2005.

[25] C. Sacristan and G. J. Kops, "Joined at the hip: kinetochores, microtubules, and spindle assembly checkpoint signaling," Trends in Cell Biology, vol. 25, no. 1, pp. 21-28, 2015.

[26] M. Carmena, M. Wheelock, H. Funabiki, and W. C. Earnshaw, "The chromosomal passenger complex (CPC): from easy rider to the godfather of mitosis," Nature Reviews Molecular Cell Biology, vol. 13, no. 12, pp. 789-803, 2012.

[27] J. P. Fededa and D. W. Gerlich, "Molecular control of animal cell cytokinesis," Nature Cell Biology, vol. 14, no. 5, pp. 440-447, 2012.

[28] R. A. Green, E. Paluch, and K. Oegema, "Cytokinesis in animal cells," Annual Review of Cell and Developmental Biology, vol. 28, pp. 29-58, 2012.

[29] F. A. Barr and U. Gruneberg, "Cytokinesis: placing and making the final cut,” Cell, vol. 131, no. 5, pp. 847-860, 2007. 
[30] M. E. Bekier, R. Fischbach, J. Lee, and W. R. Taylor, "Length of mitotic arrest induced by microtubule-stabilizing drugs determines cell death after mitotic exit," Molecular Cancer Therapeutics, vol. 8, no. 6, pp. 1646-1654, 2009.

[31] K. E. Gascoigne and S. S. Taylor, "Cancer cells display profound intra- and interline variation following prolonged exposure to antimitotic drugs," Cancer Cell, vol. 14, no. 2, pp. 111-122, 2008.

[32] D. A. Brito and C. L. Rieder, "Mitotic checkpoint slippage in humans occurs via cyclin B destruction in the presence of an active checkpoint," Current Biology, vol. 16, no. 12, pp. 1194-1200, 2006.

[33] C. H. Topham and S. S. Taylor, "Mitosis and apoptosis: how is the balance set?" Current Opinion in Cell Biology, vol. 25, no. 6, pp. 780-785, 2013.

[34] M. A. Jordan and L. Wilson, "Microtubules as a target for anticancer drugs," Nature Reviews Cancer, vol. 4, no. 4, pp. 253-265, 2004.

[35] M. Malumbres and I. P. de Castro, "Aurora kinase A inhibitors: promising agents in antitumoral therapy," Expert Opinion on Therapeutic Targets, vol. 18, no. 12, pp. 1377-1393, 2014.

[36] J. R. Brown, K. K. Koretke, M. L. Birkeland, P. Sanseau, and D. R. Patrick, "Evolutionary relationships of Aurora kinases: implications for model organism studies and the development of anti-cancer drugs," BMC Evolutionary Biology, vol. 4, article 39, 2004.

[37] E. Manchado, M. Guillamot, and M. Malumbres, "Killing cells by targeting mitosis," Cell Death and Differentiation, vol. 19, no. 3, pp. 369-377, 2012.

[38] R. Jones, J. Vuky, T. Elliott et al., "Phase II study to assess the efficacy, safety and tolerability of the mitotic spindle kinesin inhibitor AZD4877 in patients with recurrent advanced urothelial cancer," Investigational New Drugs, vol. 31, no. 4, pp. 10011007, 2013.

[39] H. L. Gomez, M. Philco, P. Pimentel et al., "Phase I doseescalation and pharmacokinetic study of ispinesib, a kinesin spindle protein inhibitor, administered on days 1 and 15 of a 28 day schedule in patients with no prior treatment for advanced breast cancer," Anticancer Drugs, vol. 23, no. 3, pp. 335-341, 2012.

[40] H. A. Burris III, S. F. Jones, D. D. Williams et al., "A phase I study of ispinesib, a kinesin spindle protein inhibitor, administered weekly for three consecutive weeks of a 28-day cycle in patients with solid tumors," Investigational New Drugs, vol. 29, no. 3, pp. 467-472, 2011.

[41] H. J. Khoury, G. Garcia-Manero, G. Borthakur et al., "A phase 1 dose-escalation study of ARRY-520, a kinesin spindle protein inhibitor, in patients with advanced myeloid leukemias," Cancer, vol. 118, no. 14, pp. 3556-3564, 2012.

[42] A. I. Marcus, U. Peters, S. L. Thomas et al., "Mitotic kinesin inhibitors induce mitotic arrest and cell death in taxol-resistant and -sensitive cancer cells," The Journal of Biological Chemistry, vol. 280, no. 12, pp. 11569-11577, 2005.

[43] X. Qian, A. McDonald, H.-J. Zhou et al., "Discovery of the first potent and selective inhibitor of centromere-associated protein E: GSK923295," ACS Medicinal Chemistry Letters, vol. 1, no. 1, pp. 30-34, 2010.

[44] V. Chung, E. I. Heath, W. R. Schelman et al., "First-time-inhuman study of GSK923295, a novel antimitotic inhibitor of centromere-associated protein e (CENP-E), in patients with refractory cancer," Cancer Chemotherapy and Pharmacology, vol. 69 , no. 3 , pp. 733-741, 2012.
[45] K. Strebhardt and A. Ullrich, "Targeting polo-like kinase 1 for cancer therapy," Nature Reviews Cancer, vol. 6, no. 4, pp. 321$330,2006$.

[46] J. Wagenblast, D. Hirth, L. Thron et al., "Effects of the polo-likekinase-1-inhibitor BI2536 in squamous cell carcinoma cell lines of the head and neck," Oncology Letters, vol. 4, no. 1, pp. 175-177, 2012.

[47] J. Wagenblast, D. Hirth, A. Eckardt et al., "Antitumoral effect of PLK-1-inhibitor BI2536 in combination with cisplatin and docetaxel in squamous cell carcinoma cell lines of the head and neck," Molecular and Clinical Oncology, vol. 1, no. 2, pp. 286290, 2013.

[48] R. Colombo, M. Caldarelli, M. Mennecozzi et al., “Targeting the mitotic checkpoint for cancer therapy with NMS-P715, an inhibitor of MPS1 kinase," Cancer Research, vol. 70, no. 24, pp. 10255-10264, 2010.

[49] R. B. Slee, B. R. Grimes, R. Bansal et al., "Selective inhibition of pancreatic ductal adenocarcinoma cell growth by the mitotic MPS1 kinase inhibitor NMS-P715," Molecular Cancer Therapeutics, vol. 13, no. 2, pp. 307-315, 2014.

[50] M. Jemaà, L. Galluzzi, O. Kepp et al., "Characterization of novel MPS1 inhibitors with preclinical anticancer activity," Cell Death and Differentiation, vol. 20, no. 11, pp. 1532-1545, 2013.

[51] B. A. Tannous, M. Kerami, P. M. van der Stoop et al., "Effects of the selective MPS1 inhibitor MPS1-IN-3 on glioblastoma sensitivity to antimitotic drugs," Journal of the National Cancer Institute, vol. 105, no. 17, pp. 1322-1331, 2013.

[52] E. Manchado, M. Guillamot, G. de Cárcer et al., “Targeting mitotic exit leads to tumor regression in vivo: modulation by Cdk1, Mastl, and the PP2A/B55 $\alpha, \delta$ phosphatase," Cancer Cell, vol. 18, no. 6, pp. 641-654, 2010.

[53] H.-C. Huang, J. Shi, J. D. Orth, and T. J. Mitchison, "Evidence that mitotic exit is a better cancer therapeutic target than spindle assembly," Cancer Cell, vol. 16, no. 4, pp. 347-358, 2009.

[54] X. Zeng, F. Sigoillot, S. Gaur et al., "Pharmacologic inhibition of the anaphase-promoting complex induces a spindle checkpoint-dependent mitotic arrest in the absence of spindle damage," Cancer Cell, vol. 18, no. 4, pp. 382-395, 2010.

[55] V. Pannu, P. C. G. Rida, A. Ogden et al., "Induction of robust de novo centrosome amplification, high-grade spindle multipolarity and metaphase catastrophe: a novel chemotherapeutic approach," Cell Death and Disease, vol. 3, no. 7, article e346, 2012.

[56] B. Rebacz, T. O. Larsen, M. H. Clausen et al., "Identification of griseofulvin as an inhibitor of centrosomal clustering in a phenotype-based screen," Cancer Research, vol. 67, no. 13, pp. 6342-6350, 2007.

[57] D. R. Wonsey and M. T. Follettie, "Loss of the forkhead transcription factor FoxM1 causes centrosome amplification and mitotic catastrophe," Cancer Research, vol. 65, no. 12, pp. 51815189, 2005.

[58] C. Vogel, C. Hager, and H. Bastians, "Mechanisms of mitotic cell death induced by chemotherapy-mediated G2 checkpoint abrogation," Cancer Research, vol. 67, no. 1, pp. 339-345, 2007.

[59] C. X. Ma, J. W. Janetka, and H. Piwnica-Worms, "Death by releasing the breaks: CHK1 inhibitors as cancer therapeutics," Trends in Molecular Medicine, vol. 17, no. 2, pp. 88-96, 2011.

[60] Q. Wang, S. Fan, A. Eastman, P. J. Worland, E. A. Sausville, and P. M. O'Connor, "UCN-01: a potent abrogator of G2 checkpoint function in cancer cells with disrupted p53," Journal of the National Cancer Institute, vol. 88, no. 14, pp. 956-965, 1996. 
[61] C. X. Ma, S. Cai, S. Li et al., "Targeting Chk1 in p53-deficient triple-negative breast cancer is therapeutically beneficial in human-in-mouse tumor models," The Journal of Clinical Investigation, vol. 122, no. 4, pp. 1541-1552, 2012.

[62] I. Gojo, A. Perl, S. Luger et al., "Phase i study of UCN-01 and perifosine in patients with relapsed and refractory acute leukemias and high-risk myelodysplastic syndrome," Investigational New Drugs, vol. 31, no. 5, pp. 1217-1227, 2013.

[63] C. X. Ma, M. J. C. Ellis, G. R. Petroni et al., "A phase II study of UCN-01 in combination with irinotecan in patients with metastatic triple negative breast cancer," Breast Cancer Research and Treatment, vol. 137, no. 2, pp. 483-492, 2013.

[64] C.-K. Lee, S. Wang, X. Huang, J. Ryder, and B. Liu, "HDAC inhibition synergistically enhances alkylator-induced DNA damage responses and apoptosis in multiple myeloma cells," Cancer Letters, vol. 296, no. 2, pp. 233-240, 2010.

[65] M. Cornago, C. Garcia-Alberich, N. Blasco-Angulo et al., "Histone deacetylase inhibitors promote glioma cell death by G2 checkpoint abrogation leading to mitotic catastrophe," Cell Death and Disease, vol. 5, no. 10, article e1435, 2014.

[66] E. J. Noh, D.-S. Lim, G. Jeong, and J.-S. Lee, "An HDAC inhibitor, trichostatin $A$, induces a delay at $\mathrm{G} 2 / \mathrm{M}$ transition, slippage of spindle checkpoint, and cell death in a transcriptiondependent manner," Biochemical and Biophysical Research Communications, vol. 378, no. 3, pp. 326-331, 2009.

[67] D. T. Terrano, M. Upreti, and T. C. Chambers, "Cyclindependent kinase 1-mediated Bcl-xL/Bcl-2 phosphorylation acts as a functional link coupling mitotic arrest and apoptosis," Molecular and Cellular Biology, vol. 30, no. 3, pp. 640-656, 2010.

[68] M. E. Harley, L. A. Allan, H. S. Sanderson, and P. R. Clarke, "Phosphorylation of Mcl-1 by CDK1-cyclin B1 initiates its Cdc20-dependent destruction during mitotic arrest," The EMBO Journal, vol. 29, no. 14, pp. 2407-2420, 2010.

[69] J. Shi, Y. Zhou, H.-C. Huang, and T. J. Mitchison, "Navitoclax (ABT-263) accelerates apoptosis during drug-induced mitotic arrest by antagonizing Bcl-xL," Cancer Research, vol. 71, no. 13, pp. 4518-4526, 2011.

[70] B. J. Tunquist, R. D. Woessner, and D. H. Walker, "Mcl-1 stability determines mitotic cell fate of human multiple myeloma tumor cells treated with the kinesin spindle protein inhibitor ARRY520," Molecular Cancer Therapeutics, vol. 9, no. 7, pp. 2046-2056, 2010.

[71] N. Sakurikar, J. M. Eichhorn, S. E. Alford, and T. C. Chambers, "Identification of a mitotic death signature in cancer cell lines," Cancer Letters, vol. 343, no. 2, pp. 232-238, 2014.

[72] S. Mac Fhearraigh and M. M. Mc Gee, "Cyclin B1 interacts with the $\mathrm{BH}$-only protein Bim and mediates its phosphorylation by Cdk1 during mitosis," Cell Cycle, vol. 10, no. 22, pp. 3886-3896, 2011.

[73] R. Gilley, P. A. Lochhead, K. Balmanno, D. Oxley, J. Clark, and S. J. Cook, "CDK1, not ERK1/2 or ERK5, is required for mitotic phosphorylation of $\mathrm{BIM}_{E L}$," Cellular Signalling, vol. 24, no. 1, pp. 170-180, 2012.

[74] P. E. Czabotar, G. Lessene, A. Strasser, and J. M. Adams, "Control of apoptosis by the BCL-2 protein family: implications for physiology and therapy," Nature Reviews Molecular Cell Biology, vol. 15, no. 1, pp. 49-63, 2014.

[75] C. R. Han, D. Y. Jun, J. Y. Lee, and Y. H. Kim, "Prometaphase arrest-dependent phosphorylation of $\mathrm{Bcl}-2$ and Bim reduces the association of Bcl-2 with Bak or Bim, provoking Bak activation and mitochondrial apoptosis in nocodazole-treated Jurkat $\mathrm{T}$ cells," Apoptosis, vol. 19, no. 1, pp. 224-240, 2014.
[76] M. Upreti, E. N. Galitovskaya, R. Chu et al., "Identification of the major phosphorylation site in $\mathrm{Bcl}-\mathrm{xL}$ induced by microtubule inhibitors and analysis of its functional significance," The Journal of Biological Chemistry, vol. 283, no. 51, pp. 35517-35525, 2008.

[77] I. E. Wertz, S. Kusam, C. Lam et al., "Sensitivity to antitubulin chemotherapeutics is regulated by MCL1 and FBW7," Nature, vol. 471, no. 7336, pp. 110-114, 2011.

[78] O. Kutuk and A. Letai, "Displacement of Bim by Bmf and Puma rather than increase in Bim level mediates paclitaxel-induced apoptosis in breast cancer cells," Cell Death and Differentiation, vol. 17, no. 10, pp. 1624-1635, 2010.

[79] Z. Li, J. Zhang, Z. Liu, C.-W. Woo, and C. J. Thiele, "Downregulation of Bim by brain-derived neurotrophic factor activation of TrkB protects neuroblastoma cells from paclitaxel but not etoposide or cisplatin-induced cell death," Cell Death and Differentiation, vol. 14, no. 2, pp. 318-326, 2007.

[80] R. Li, T. Moudgil, H. J. Ross, and H.-M. Hu, "Apoptosis of non-small-cell lung cancer cell lines after paclitaxel treatment involves the BH3-only proapoptotic protein Bim," Cell Death and Differentiation, vol. 12, no. 3, pp. 292-303, 2005.

[81] T. Kawabata, S. Tanimura, K. Asai, R. Kawasaki, Y. Matsumaru, and M. Kohno, "Up-regulation of pro-apoptotic protein bim and down-regulation of anti-apoptotic protein Mcl-1 cooperatively mediate enhanced tumor cell death induced by the combination of ERK kinase (MEK) inhibitor and microtubule inhibitor," The Journal of Biological Chemistry, vol. 287, no. 13, pp. 10289-10300, 2012.

[82] A. V. Miller, M. A. Hicks, W. Nakajima, A. C. Richardson, J. J. Windle, and H. Harada, "Paclitaxel-induced apoptosis Is BAKdependent, but BAX and BIM-independent in breast tumor," PLoS ONE, vol. 8, no. 4, Article ID e60685, 2013.

[83] J. L. Andersen, C. E. Johnson, C. D. Freel et al., "Restraint of apoptosis during mitosis through interdomain phosphorylation of caspase-2," The EMBO Journal, vol. 28, no. 20, pp. 3216-3227, 2009.

[84] L. A. Allan and P. R. Clarke, "Phosphorylation of caspase9 by $\mathrm{CDK} 1 /$ cyclin $\mathrm{B} 1$ protects mitotic cells against apoptosis," Molecular Cell, vol. 26, no. 2, pp. 301-310, 2007.

[85] Y. Matthess, M. Raab, M. Sanhaji, I. N. Lavrik, and K. Strebhardt, "Cdk1/Cyclin B1 controls fas-mediated apoptosis by regulating caspase-8 activity," Molecular and Cellular Biology, vol. 30, no. 24, pp. 5726-5740, 2010.

[86] K. Lee, A. E. Kenny, and C. L. Rieder, "Caspase activity is not required for the mitotic checkpoint or mitotic slippage in human cells," Molecular Biology of the Cell, vol. 22, no. 14, pp. 2470-2479, 2011.

[87] M. C. Wei, W.-X. Zong, E. H.-Y. Cheng et al., "Proapoptotic BAX and BAK: a requisite gateway to mitochondrial dysfunction and death," Science, vol. 292, no. 5517, pp. 727-730, 2001.

[88] S. M. Kilbride and J. H. M. Prehn, "Central roles of apoptotic proteins in mitochondrial function," Oncogene, vol. 32, no. 22, pp. 2703-2711, 2013.

[89] S. P. Wheatley and I. A. McNeish, "Survivin: a protein with dual roles in mitosis and apoptosis," International Review of Cytology, vol. 247, pp. 35-88, 2005.

[90] D. S. O’Donovan, S. MacFhearraigh, J. Whitfield, L. B. Swigart, G. I. Evan, and M. M. Mc Gee, "Sequential Cdk1 and Plk1 phosphorylation of protein tyrosine phosphatase $1 \mathrm{~B}$ promotes mitotic cell death.", Cell Death \& Disease, vol. 4, article e468, 2013. 
[91] A. B. Harbauer, M. Opalińska, C. Gerbeth et al., "Cell cycledependent regulation of mitochondrial preprotein translocase," Science, vol. 346, no. 6213, pp. 1109-1113, 2014.

[92] Z. Wang, M. Fan, D. Candas et al., "Cyclin B1/Cdk1 coordinates mitochondrial respiration for cell-cycle G2/M progression," Developmental Cell, vol. 29, no. 2, pp. 217-232, 2014.

[93] M. K. Gardner, M. Zanic, and J. Howard, "Microtubule catastrophe and rescue," Current Opinion in Cell Biology, vol. 25, no. 1, pp. 14-22, 2013.

[94] F. Herzog, I. Primorac, P. Dube et al., "Structure of the anaphase-promoting complex/cyclosome interacting with a mitotic checkpoint complex," Science, vol. 323, no. 5920, pp. 1477-1481, 2009.

[95] A. Musacchio and E. D. Salmon, "The spindle-assembly checkpoint in space and time," Nature Reviews Molecular Cell Biology, vol. 8, no. 5, pp. 379-393, 2007.

[96] A. Burgess, M. Rasouli, and S. Rogers, "Stressing mitosis to death," Frontiers in Oncology, vol. 4, article 140, 2014.

[97] A. E. Kelly and H. Funabiki, "Correcting aberrant kinetochore microtubule attachments: an Aurora B-centric view," Current Opinion in Cell Biology, vol. 21, no. 1, pp. 51-58, 2009.

[98] T. J. Maresca and E. D. Salmon, "Welcome to a new kind of tension: translating kinetochore mechanics into a waitanaphase signal," Journal of Cell Science, vol. 123, part 6, pp. 825835, 2010.

[99] A. Janssen, G. J. P. L. Kops, and R. H. Medema, "Elevating the frequency of chromosome mis-segregation as a strategy to kill tumor cells," Proceedings of the National Academy of Sciences of the United States of America, vol. 106, no. 45, pp. 19108-19113, 2009.

[100] M. Malumbres, "Physiological relevance of cell cycle kinases," Physiological Reviews, vol. 91, no. 3, pp. 973-1007, 2011.

[101] M. Carmena and W. C. Earnshaw, "The cellular geography of aurora kinases," Nature Reviews Molecular Cell Biology, vol. 4, no. 11, pp. 842-854, 2003.

[102] S. M. A. Lens, E. E. Voest, and R. H. Medema, "Shared and separate functions of polo-like kinases and aurora kinases in cancer," Nature Reviews Cancer, vol. 10, no. 12, pp. 825-841, 2010.

[103] H. Zhou, J. Kuang, L. Zhong et al., “Tumour amplified kinase STK15/BTAK induces centrosome amplification, aneuploidy and transformation," Nature Genetics, vol. 20, no. 2, pp. 189-193, 1998.

[104] F. Girdler, K. E. Gascoigne, P. A. Eyers et al., "Validating Aurora B as an anti-cancer drug target," Journal of Cell Science, vol. 119, no. 17, pp. 3664-3675, 2006.

[105] X. Liu and M. Winey, "The MPS1 family of protein kinases," Annual Review of Biochemistry, vol. 81, pp. 561-585, 2012.

[106] F. A. Barr, H. H. W. Silljé, and E. A. Nigg, "Polo-like kinases and the orchestration of cell division," Nature Reviews Molecular Cell Biology, vol. 5, no. 6, pp. 429-440, 2004.

[107] M. Kimura, T. Yoshioka, M. Saio, Y. Banno, H. Nagaoka, and Y. Okano, "Mitotic catastrophe and cell death induced by depletion of centrosomal proteins," Cell Death and Disease, vol. 4, no. 4, article e603, 2013.

[108] T. Mayor, P. Meraldi, Y.-D. Stierhof, E. A. Nigg, and A. M. Fry, "Protein kinases in control of the centrosome cycle," FEBS Letters, vol. 452, no. 1-2, pp. 92-95, 1999.

[109] E. Doménech and M. Malumbres, "Mitosis-targeting therapies: a troubleshooting guide," Current Opinion in Pharmacology, vol. 13, no. 4, pp. 519-528, 2013.
[110] X. Yao, A. Abrieu, Y. Zheng, K. F. Sullivan, and D. W. Cleveland, "CENP-E forms a link between attachment of spindle microtubules to kinetochores and the mitotic checkpoint," Nature Cell Biology, vol. 2, no. 8, pp. 484-491, 2000.

[111] B. A. A. Weaver, Z. Q. Bonday, F. R. Putkey, G. J. P. L. Kops, A. D. Silk, and D. W. Cleveland, "Centromere-associated protein$\mathrm{E}$ is essential for the mammalian mitotic checkpoint to prevent aneuploidy due to single chromosome loss," Journal of Cell Biology, vol. 162, no. 4, pp. 551-563, 2003.

[112] U. S. Eggert, T. J. Mitchison, and C. M. Field, "Animal cytokinesis: from parts list to mechanisms," Annual Review of Biochemistry, vol. 75, pp. 543-566, 2006.

[113] H. Vakifahmetoglu, M. Olsson, and B. Zhivotovsky, "Death through a tragedy: mitotic catastrophe," Cell Death and Differentiation, vol. 15, no. 7, pp. 1153-1162, 2008.

[114] N. Bucher and C. D. Britten, "G2 checkpoint abrogation and checkpoint kinase-1 targeting in the treatment of cancer," British Journal of Cancer, vol. 98, no. 3, pp. 523-528, 2008.

[115] R. Boutros, C. Dozier, and B. Ducommun, "The when and wheres of CDC25 phosphatases," Current Opinion in Cell Biology, vol. 18, no. 2, pp. 185-191, 2006.

[116] M. A. Mackey, X. F. Zhang, C. R. Hunt et al., "Uncoupling of Mphase kinase activation from the completion of S-phase by heat shock," Cancer Research, vol. 56, no. 8, pp. 1770-1774, 1996.

[117] T. A. Chan, H. Hermeking, C. Lengauer, K. W. Kinzler, and B. Vogelstein, "14-3-3 $\sigma$ is required to prevent mitotic catastrophe after DNA damage," Nature, vol. 401, no. 6753, pp. 616-620, 1999.

[118] M. Castedo, J.-L. Perfettini, T. Roumier et al., "The cell cycle checkpoint kinase Chk2 is a negative regulator of mitotic catastrophe," Oncogene, vol. 23, no. 25, pp. 4353-4361, 2004.

[119] H. Vakifahmetoglu, M. Olsson, C. Tamm, N. Heidari, S. Orrenius, and B. Zhivotovsky, "DNA damage induces two distinct modes of cell death in ovarian carcinomas," Cell Death and Differentiation, vol. 15, no. 3, pp. 555-566, 2008.

[120] H. Vakifahmetoglu, M. Olsson, S. Orrenius, and B. Zhivotovsky, "Functional connection between p53 and caspase-2 is essential for apoptosis induced by DNA damage," Oncogene, vol. 25, no. 41, pp. 5683-5692, 2006.

[121] A.-L. Salmela and M. J. Kallio, "Mitosis as an anti-cancer drug target," Chromosoma, vol. 122, no. 5, pp. 431-449, 2013.

[122] M. Kavallaris, "Microtubules and resistance to tubulin-binding agents," Nature Reviews Cancer, vol. 10, no. 3, pp. 194-204, 2010.

[123] Y. Huang, A. M. Ibrado, J. C. Reed et al., "Co-expression of several molecular mechanisms of multidrug resistance and their significance for paclitaxel cytotoxicity in human AML HL-60 cells," Leukemia, vol. 11, no. 2, pp. 253-257, 1997.

[124] D. Huszar, M.-E. Theoclitou, J. Skolnik, and R. Herbst, "Kinesin motor proteins as targets for cancer therapy," Cancer and Metastasis Reviews, vol. 28, no. 1-2, pp. 197-208, 2009.

[125] H. Dixon and C. J. Norbury, "Therapeutic exploitation of checkpoint defects in cancer cells lacking p53 function," Cell Cycle, vol. 1, no. 6, pp. 362-368, 2002.

[126] Y. Xiao, J. Ramiscal, K. Kowanetz et al., "Identification of preferred chemotherapeutics for combining with a CHK1 Inhibitor," Molecular Cancer Therapeutics, vol. 12, no. 11, pp. 22852295, 2013.

[127] P. C. de Witt Hamer, S. E. Mir, D. Noske, C. J. F. van Noorden, and T. Würdinger, "WEE1 kinase targeting combined with DNA-damaging cancer therapy catalyzes mitotic catastrophe," Clinical Cancer Research, vol. 17, no. 13, pp. 4200-4207, 2011. 
[128] K.-S. Chan, C.-G. Koh, and H.-Y. Li, "Mitosis-targeted anticancer therapies: where they stand," Cell Death and Disease, vol. 3, no. 10, article e411, 2012.

[129] T. J. Mitchison, "The proliferation rate paradox in antimitotic chemotherapy," Molecular Biology of the Cell, vol. 23, no. 1, pp. $1-6,2012$.

[130] E. Komlodi-Pasztor, D. L. Sackett, and A. T. Fojo, "Inhibitors targeting mitosis: tales of how great drugs against a promising target were brought down by a flawed rationale," Clinical Cancer Research, vol. 18, no. 1, pp. 51-63, 2012.

[131] B. A. A. Weaver and D. W. Cleveland, "Decoding the links between mitosis, cancer, and chemotherapy: the mitotic checkpoint, adaptation, and cell death," Cancer Cell, vol. 8, no. 1, pp. 7-12, 2005.

[132] W. Tao, V. J. South, Y. Zhang et al., "Induction of apoptosis by an inhibitor of the mitotic kinesin KSP requires both activation of the spindle assembly checkpoint and mitotic slippage," Cancer Cell, vol. 8, no. 1, pp. 49-59, 2005.

[133] M. Chircop, S. Perera, A. Mariana et al., "Inhibition of dynamin by dynole 34-2 induces cell death following cytokinesis failure in cancer cells," Molecular Cancer Therapeutics, vol.10, no. 9, pp. 1553-1562, 2011.

[134] J. D. Kessler, K. T. Kahle, T. Sun et al., "A SUMOylationdependent transcriptional subprogram is required for Mycdriven tumorigenesis," Science, vol. 335, no. 6066, pp. 348-353, 2012.

[135] D. Annibali, J. R. Whitfield, E. Favuzzi et al., "Myc inhibition is effective against glioma and reveals a role for Myc in proficient mitosis," Nature Communications, vol. 5, article 4632, 2014.

[136] L. Lu, H. Han, Y. Tian et al., "Aurora kinase A mediates cMyc's oncogenic effects in hepatocellular carcinoma," Molecular Carcinogenesis, 2014.

[137] W. C. Gustafson, J. G. Meyerowitz, E. A. Nekritz et al., "Drugging MYCN through an allosteric transition in Aurora kinase A," Cancer Cell, vol. 26, no. 3, pp. 414-427, 2014. 


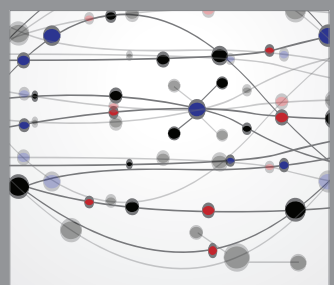

The Scientific World Journal
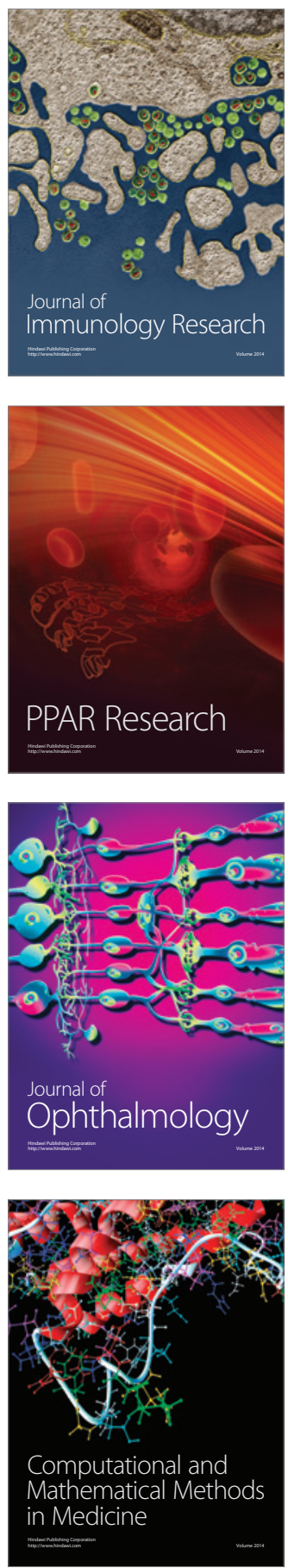

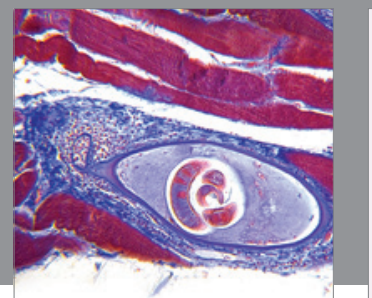

Gastroenterology

Research and Practice
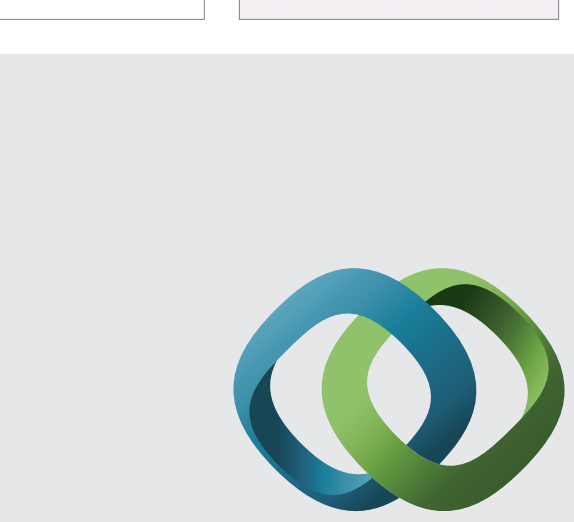

\section{Hindawi}

Submit your manuscripts at

http://www.hindawi.com
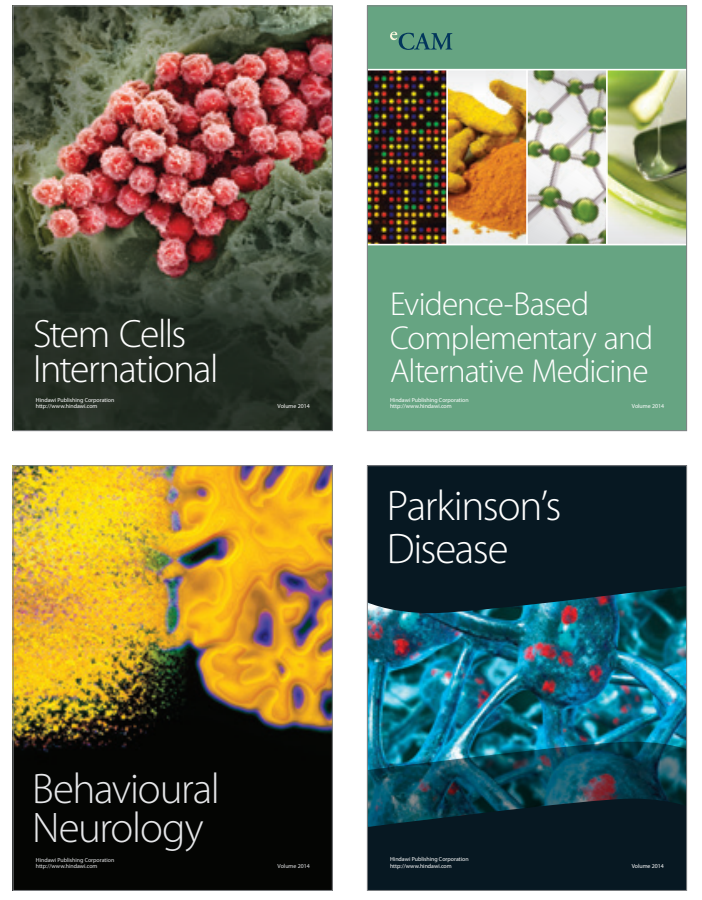
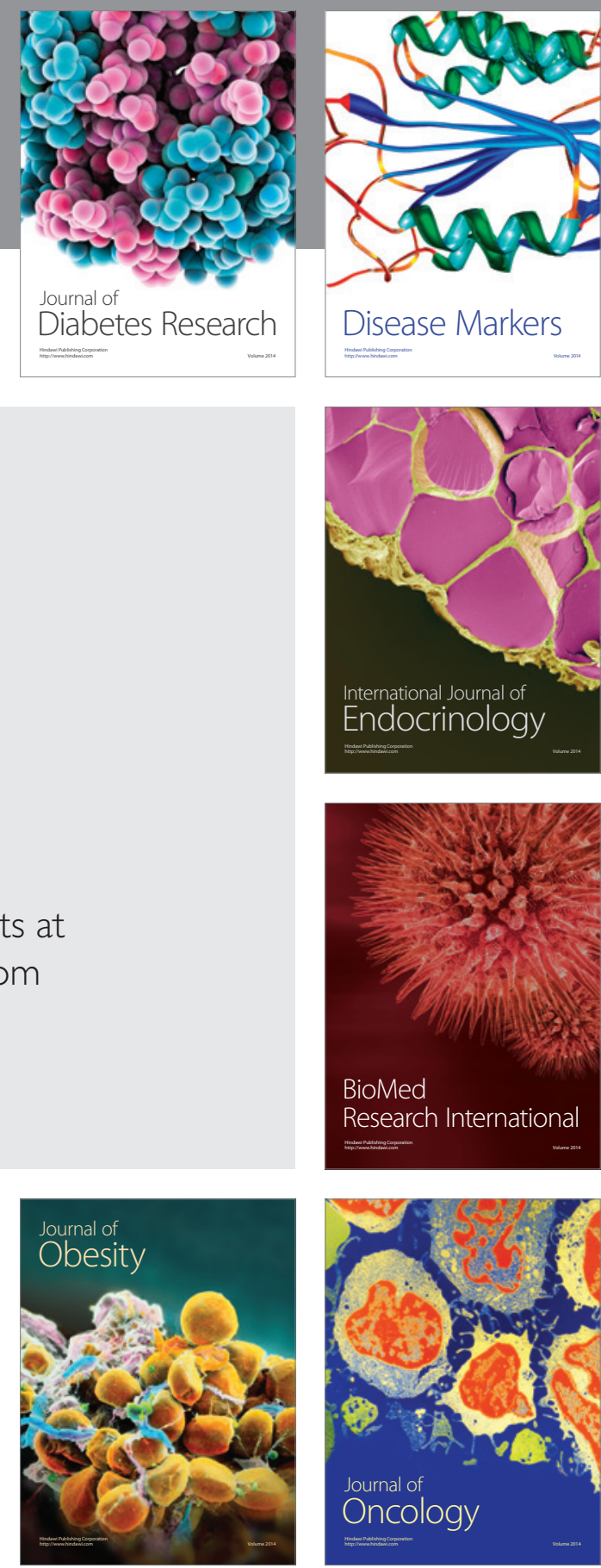

Disease Markers
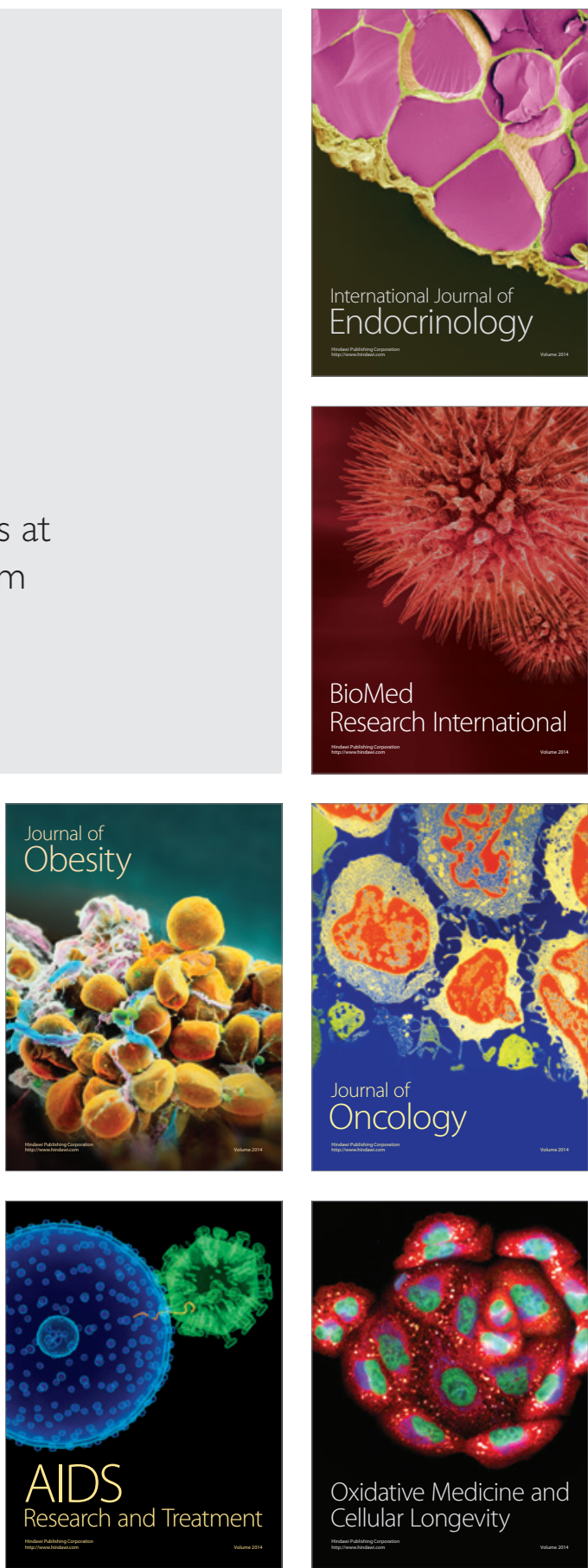